\title{
FEM Modeling of Shear Cutting of Electrical Steel Sheets under Various Technological Conditions
}

\author{
Ján Slota ${ }^{1, *}$, Luboš Kaščák ${ }^{1}$, Stanislaw Kut ${ }^{2}$ \\ ${ }^{1}$ Technical university of Košice, Faculty of Mechanical Engineering, Department of Computer Support of Technology, Mäsiarska 74, 04001 Košice, \\ Slovak Republic \\ ${ }^{2}$ Rzeszow University of Technology, Faculty of Mechanical Engineering and Aeronautics, Department of Materials Forming and Processing, Rzeszów, \\ Poland
}

\begin{abstract}
Almost all electrical machine consists of the stator and rotor cores, which are made of stacked non-oriented electric steel sheets. Punching and blanking are the two commonly used shear cutting technologies. The efficiency and performance of an electrical machine depend on the magnetic properties of its magnetic core. The shear cutting process causes the formation of residual stresses in cut segments next to the cutting line from the nonoriented electrical sheet metal, resulting in increased iron losses. The extent of deterioration in the magnetic material properties depends on the amount of induced stresses, which is affected by the used process parameters during shear cutting and the mechanical properties of the electrical steel sheets. This paper focuses on the residual stresses induced by punching with different shear cutting conditions using finite element analysis. Influence of cutting clearance of the shear cutting tool on were observed.
\end{abstract}

Keywords: electrical steel sheet; shear cutting; cutting clearance; residual stress; blunt cutting edge.

\section{Introduction}

The electrotechnical industry produces various types of electrical machines and apparatus in which a magnetic circuit is used. The alternating magnetic circuits consist of individual electrically insulated sheets with good magnetic properties. A higher Si content of the steel causes significant increasing in electrical resistance and permeability. Increasing the resistivity of steel means suppressing of specific losses and thus reducing overall magnetic losses. In practice, sheets with a Si content of 0.3 to $4.6 \%$ are used. Magnetic quality and practical usability of silicon steel for the electrotechnical industry depend on the content of Si, sheet thickness, and technology of manufacturing.

Shear cutting in a cutting tool and the laser cutting are the two most commonly used technologies for producing electrical machine segments (mainly the stator and the rotor core). While laser cutting is often associated with making prototypes, shear cutting is utilized to produce a large number of these components [1]. Regardless of which of these technologies is used, it change the magnetic properties of the produced segments $[1,2,6]$. This change is mainly due to the fact, that plastic and elastic deformations lead to residual stress of the cutting segment, which is induced next to the cutting surface. Although a lot of research has been conducted in this area [3-9], the distribution of residual stresses around the cutting edge and its impact on magnetic losses is still the subject of research. 
When a segment containing residual stresses is magnetized, these stresses prevent the magnetic domains from being aligned in the direction of the outer magnetic field [2]. The extent of this effect is determined by the residual stresses [7].

According to $[2,5,6]$, a smaller cutting clearance provides better magnetic properties of the specimens than a large cutting clearance. The effect of a worn cutting tool is significant as well. Research suggests that larger cutting clearance and increasing wear on the cutting edge of the tool lead to higher watt losses and deterioration in magnetic properties.

In this work, the effect of the size of the cutting clearance of the tool on the size and distribution of the residual stresses in the cutting samples was investigated both experimentally ad by means of the FE analysis.

\section{Experimental Materials and Methods}

The annular shape of the punched parts with the same cutting clearance in the inner and outer diameters of the toroid was used for the investigation of shear cutting conditions of sheet metal for the electrotechnical industry. The shape and dimensions of the blank (specimen) are shown in Figure 1.

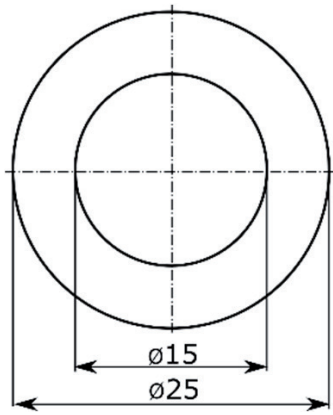

Fig. 1: Shape and dimensions of the specimen.

The specimen is suitable for not only the research of optimal shear cutting process parameters, but also for the subsequent evaluation of both magnetic properties and watt losses. From the point of view of the geometric quality of the blank (Figure 2), the determination of the beginning of the ductile phase and the trajectory of the fracture are a very important aspects of the analysis. The fracture starts at a location near the cutting edge, where the deformation reaches the limit value.



Fig. 2: The theoretical profile of the shear cutting surface: $h_{R}$ - rollover, $h_{C}$ - clean cut, $h_{F}$ - fracture, $h_{B}$ - burr height, $t_{0}$ - sheet thickness.

An experimental shear cutting tool was used to the punching of ring-shaped annular parts from electrical sheet metal in a finishing state with four different cutting clearances corresponding to $1 \%$, $3 \%, 5 \%$ and $7 \%$ of the sheet thickness. The chemical composition of two grades of the electrical steel sheets used in the experiment is shown in Table 1. The material has a Si content of 0.574 wt\%. High Si contents lead to higher material hardness, higher ultimate tensile strength, and lower uniform elongation. The specific loss decreases with increasing silicon content at constant sheet metal thickness. Mechanical characteristics like yield stress, ultimate tensile strength or elongation are determined in tensile test according to EN ISO 6892-1. The basic mechanical properties of the investigated sheet metal are shown in Table 2.

A die and the punch radius of $R_{s}=R_{m}=10 \mu \mathrm{m}$ was used, which should simulate a sharp shear cutting tool. Determination of these values is based on real instrument measurement after grinding of the tool. The specimens for the measurement were produced with shear cutting velocity of $0.2 \mathrm{~m} / \mathrm{s}$. The effect of cutting speed in this work was not evaluated.

The shearcutting processes are preferably modeled using the finite element method in the range of elastic and plastic deformations until the start of the fracture phase, which is usually determined by some of the generally accepted fracture criterion such as Cockroft-Latham, Rice-Tracey, Oyane, Atkins, Goijaerts, Johnson-Cook and others. The simulation model was solved in MSC MARCTM FEM software using an advanced nonlinear solver. Due to the planar symmetry of the blank, a half twodimensional simulation model was created (Figure 3). The model was solved in plane strain condition. 
Tab. 1: Chemical composition of the electrical steel sheet EP530-50A [wt \%].

\begin{tabular}{|l|l|l|l|l|l|l|l|l|l|l|l|}
\hline C & Mn & Si & P & S & Al & Cu & Ni & Cr & As & Ti & V \\
\hline 0.0059 & 0.506 & 0.574 & 0.034 & 0.0036 & 0.418 & 0.011 & 0.010 & 0.019 & $<0.001$ & 0.001 & $<0.001$ \\
\hline $\mathrm{Nb}$ & $\mathrm{Mo}$ & $\mathrm{Co}$ & $\mathrm{Sn}$ & $\mathrm{Sb}$ & $\mathrm{W}$ & $\mathrm{B}$ & $\mathrm{Ca}$ & $\mathrm{Zr}$ & $\mathrm{N} 2$ & 02 & Als \\
\hline$<0.002$ & 0.003 & $<0.002$ & $<0.002$ & $<0.002$ & $<0.003$ & $<0.0002$ & $<0.0002$ & $<0.001$ & 0.0017 & 0.0041 & 0.416 \\
\hline
\end{tabular}

Tab. 2: Mechanical properties of the electrical steel sheet EP530-50A.

\begin{tabular}{|l|l|l|l|l|l|l|}
\hline Material & $\begin{array}{l}\text { Thickness } \\
{[\mathrm{mm}]}\end{array}$ & $\begin{array}{l}\mathrm{E} \\
{[\mathrm{GPa}]}\end{array}$ & $\begin{array}{l}\text { Rp0,2 } \\
{[\mathrm{MPa}]}\end{array}$ & $\begin{array}{l}\mathrm{Rm} \\
{[\mathrm{MPa}]}\end{array}$ & $\begin{array}{l}\text { Ag } \\
{[\%]}\end{array}$ & $\begin{array}{l}\text { A50 } \\
{[\%]}\end{array}$ \\
\hline EP530-50A & 0.52 & 213 & 413 & 477 & 9.6 & 17.0 \\
\hline
\end{tabular}

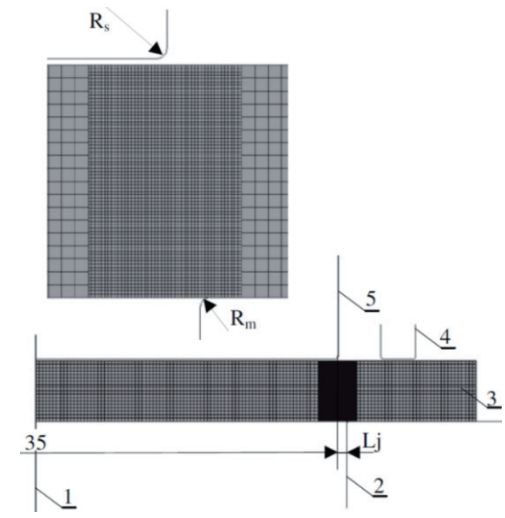

Fig. 3: FEM model of the shear cutting process. (1) - symmetry plane, (2) - die, (3) - sheet metal, (4) - blankholder, (5) - punch, $L_{j}$-cutting clearance, $R_{s}$ - punch radius, $R_{m}$ - die radius.

In order to create a mesh on the blank, square elements from $0.025 \mathrm{~mm}$ to $0.005 \mathrm{~mm}$ size next to cutting surface were used. The size of elements outside of this area was set to $0.05 \mathrm{~mm}$ with global remeshing for blank. The Coulomb friction model defined the contact between the tool, and the electrical steel sheet with the friction coefficient was set to 0.1. An elastoplastic constitutive model of the $\mathrm{H}-\mathrm{M}-\mathrm{H}$ yield criterion with the isotropic hardening described material properties of the blank. The hardening curve of tested electrical steel sheet was extrapolated by Hollomon (Ludwik) model - Table 3.

Tab. 3: Hardening curve extrapolated from the tensile test.

\begin{tabular}{|l|l|l|}
\hline Material & Hollomon (Ludwik) \\
\hline & K [MPa] & $n$ \\
\hline EP530-50A & 648 & 0.081 \\
\hline
\end{tabular}

The Cocroft-Latham fracture model (1) as the fracture criterion was used.

$$
C=\int_{0}^{\varepsilon_{f}} \frac{\sigma_{m}}{\bar{\sigma}} d \bar{\varepsilon}
$$

where $\sigma_{m}$ is the maximum component of the tensile stress, $\bar{\varepsilon}$ is the effective strain, $\bar{\sigma}$ is the effective stress, and $C$ is the constant indicating the initiation of the crack. Since the aim of this FE analysis was to qualitatively compare the residual stresses in the specimens after the shear cutting process, the hardening curve and the fracture model were calibrated both based on the "punch force vs. punch travel" and on the shear surface analysis. Figure 4 and 5 shows the punch penetration and what kind of the fracture (separation) occurred in the blank.

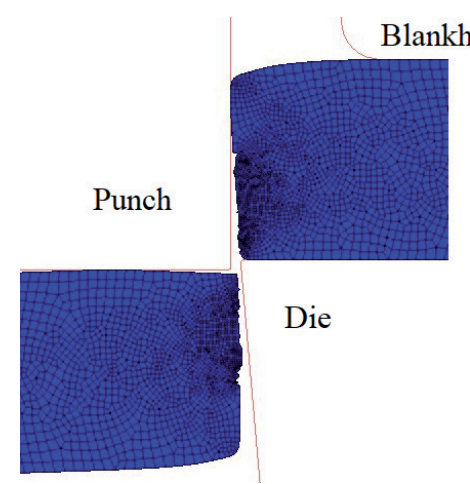

Fig. 4: Punch penetration and separation of blank; sharp cutting edge.

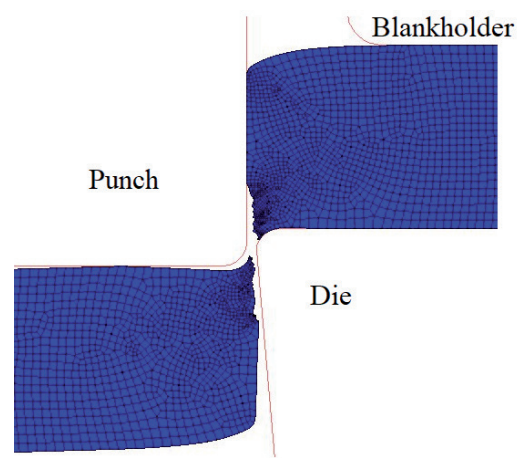

Fig. 5: Punch penetration and separation of blank; worn cutting edge. 


\section{Results and Discussion}

The results of the FE analysis (Figures 6-13) show the residual stress distribution in the cutting surface. The results of shear cutting process with a sharp tool edge $\left(R_{s}=R_{m}=0.01 \mathrm{~mm}\right)$ are presented in Figures $6,8,10$ and 12 the results of worn tool edge are presented in Figures 7, 9, 11 and $13\left(R_{s}=R_{m}=0.07\right.$ $\mathrm{mm}$ ). The results of residual stress distribution show that the largest residual stresses occur next to the cutting surface where the fracture begins. The effect of the change in the cutting clearance and worn cutting edges of the tool is also evident from Figures 6 - 13. The depth of penetration of residual stresses in the area of the cutting surface was significantly lower when shear-cutting process was performed with smaller cutting clearance. In contrast, the FEA showed that smaller cutting clearances may lead to higher residual stresses next to the cutting surface. The results also show the effect of worn cutting edge on the burr height.

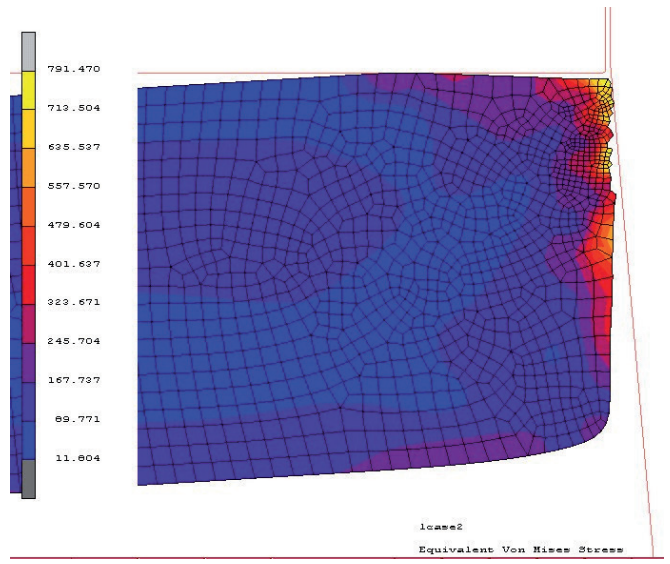

Fig. 6: Residual stress distribution, $\sigma_{\text {red }} L_{j}=1 \%$, sharp cutting edge.

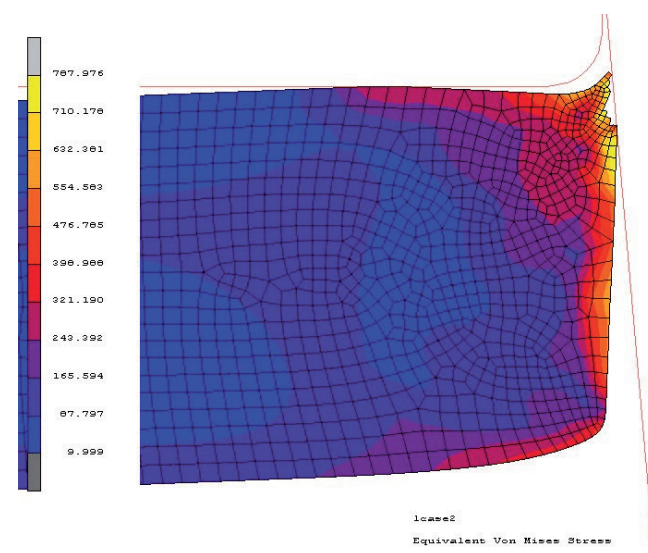

Fig. 7: Residual stress distribution, $\sigma_{\text {red' }} L_{j}=1 \%$, worn cutting edge.

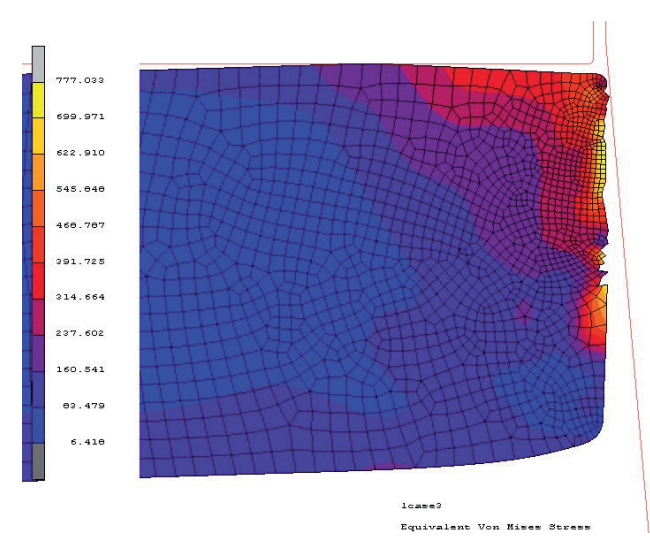

Fig. 8: Residual stress distribution, $\sigma_{\text {red' }} L_{j}=3 \%$, sharp cutting edge.

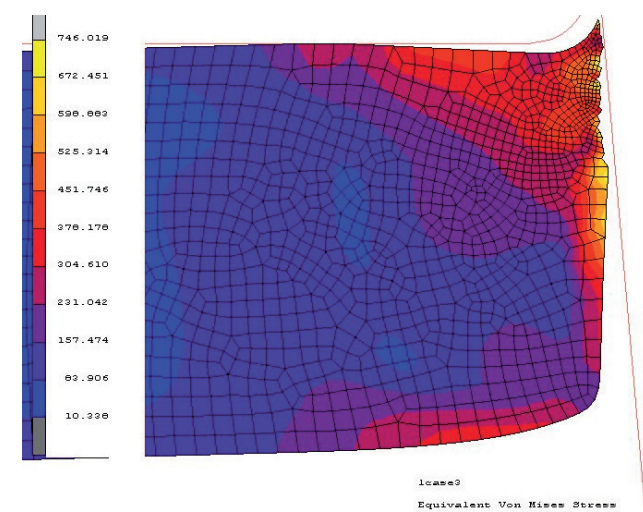

Fig. 9: Residual stress distribution, $\sigma_{\text {red }} L_{j}=3 \%$, worn cutting edge

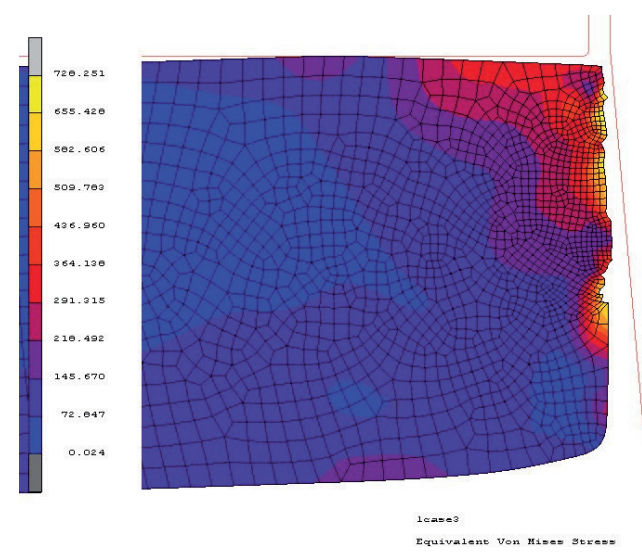

Fig. 10: Residual stress distribution, $\sigma_{\text {red }} L_{j}=5 \%$, sharp cutting edge. 


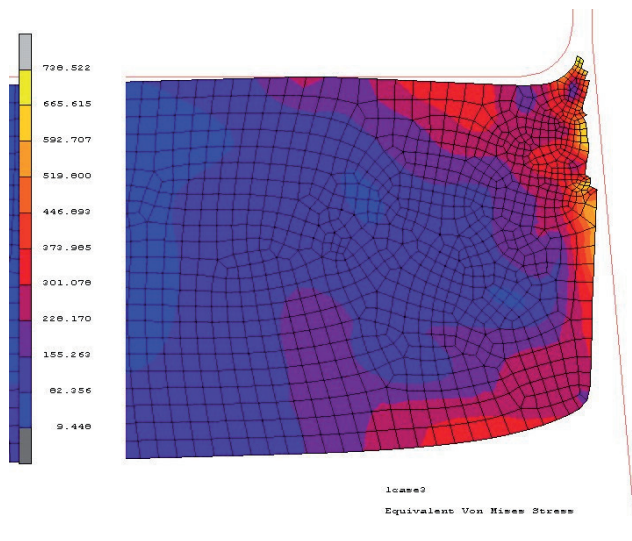

Fig. 11: Residual stress distribution, $\sigma_{\text {red }}, L_{j}=5 \%$, worn cutting edge.

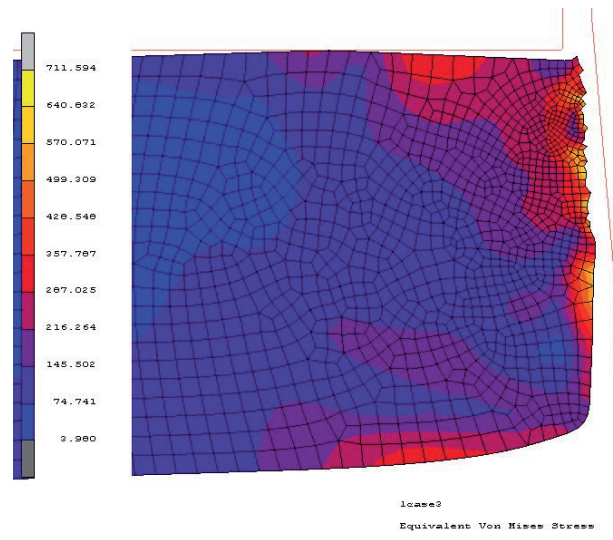

Fig. 12: Residual stress distribution, $\sigma_{\text {red }} L_{j}=7 \%$, sharp cutting edge.

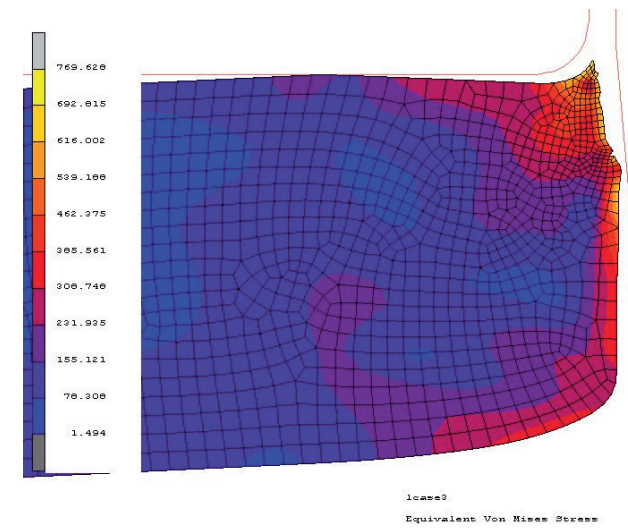

Fig. 13: Residual stress distribution, $\sigma_{\text {red }} L_{j}=7 \%$, worn cutting edge.

Similarly, if a tool with sharp cutting edge is used, the residual stresses are lower than those with the worn cutting edge. The results also show that a smaller cutting clearance as well as a sharp cutting edge reduces the size of the area affected by shearing. Furthermore, the results show that the increasing cutting clearance led to increasing of the shear zone $h_{F}$ on the cutting surface. These results were confirmed by real-time experiments. The influence of the cutting clearance on the shear zone $h_{F}$ of the cutting surface is shown in Figure 14. The course of the punch force is shown on Figure 15.

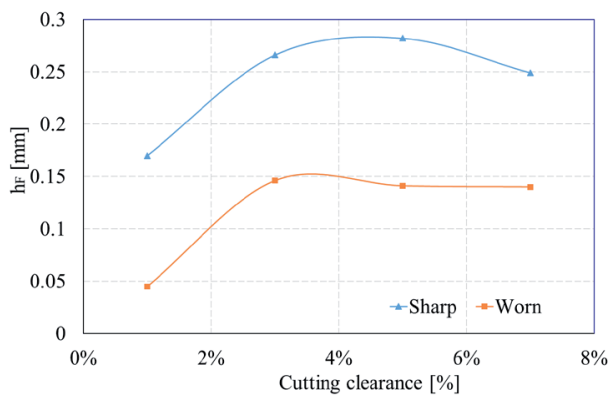

Fig. 14: The influence of the cutting clearance on the size of the shear zone $h_{F}$

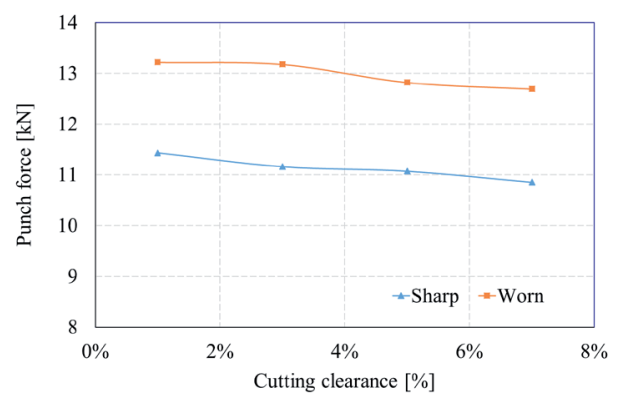

Fig. 15: The influence of the cutting clearance on the punch force.

The real experiments with the shear cutting tool were performed to verify the results obtained from numerical simulations. The shear cutting process was performed using an experimental punching tool (Figure 16) on a hydraulic press in laboratory conditions. The machine consisted of force and stroke sensors and automatic recording of the "Force-stroke" data on a computer. The punch force over punch stroke curves comparison for the cutting clearance of 5\% is shown in Figure 17.

The characteristics of the course of the punch forces were determined in relation to the punch stroke. It can be noted the FEM modeling of the shear cutting process is an effective tool to evaluate the influence of both the cutting process parameters and wear state of the cutting edge. 


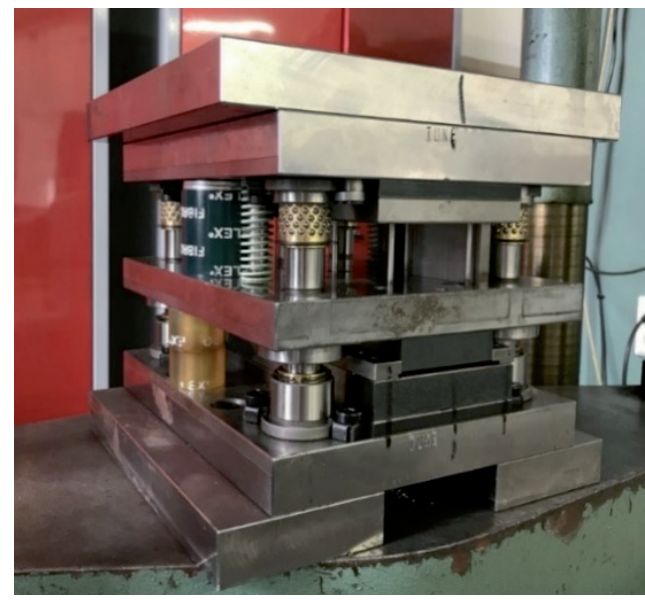

Fig. 16: Experimental shear cutting tool.

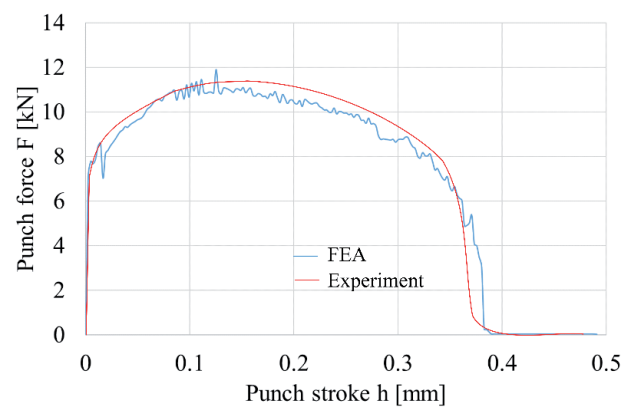

Fig. 17: The punch force over punch stroke comparison for the cutting clearance $L_{i}=5 \%$.

\section{Conclusion}

From the point of view of improving the quality of the stator and rotor cores of the electrical machines as well as the transformers, it is crucial to handle the shear cutting process in the punching tool so that this process should minimally affects the shear surface. The cutting clearance and wear state of the punch and die have a significant influence on the induced residual stress when shear cutting electrical steel sheets. The sharp tool edge always leads to better results than the worn cutting edge. The depth of the penetration of residual stresses in the area of the cutting surface is significantly lower when shear cutting process was performed with smaller cutting clearance. In contrast, the FEA showed that smaller cutting clearances may lead to higher residual stresses next to the cutting surface. The results show the effect of worn cutting edge on the burr height as well.

Worn cutting edge of the cutting tool results in a deterioration of the cutting surface quality in all the cutting clearances. There is an increase of the burr height as well as the depth of penetration of residual stresses in the cutting zone is higher. The greatest changes in the quality of the cutting surface were observed with the largest cutting clearance (7\%). Also, there is a greater distribution of residual stresses from the cutting surface inside the specimen, which causes deterioration of the magnetic properties and increases of the specific losses. It is possible to change the final magnetic properties of the individual technological processes of shear cut samples for rotor and stator cores of electrical machines by changing the cutting clearance, depending on their application.

\section{Acknowledgments}

\section{This work was supported by the project APVV-14-0834.}

\section{References and Notes}

[1] Emura, M., Landgraf, F.J.G., Ross, W., Barreta, J.R. (2003). The influence of cutting technique on the magnetic properties of electrical steels. Journal of Magnetism and Magnetic Materials, Vol. 254-255, pp. 358-360.

[2] Weiss, H.A., Leuning, N., Steentjes, S., Hameyer, K., Andorfer, T., Jenner, S., Volk, W. (2017) Influence of shear cutting parameters on the electromagnetic properties of non-oriented electrical steel sheets. Journal of Magnetism and Magnetic Materials, Vol. 421, pp. 250-259.

[3] Siebert, R., Schneider, J., Beyer, E. (2014). Laser cutting and mechanical cutting of electrical steels and its effect on the magnetic properties. IEEE Transactions on Magnetics, Vol. 50, No. 4, pp. 1-4.

[4] Spišák, E., Majerníková, J., Kaščák, L., Slota, J. (2015). Influence of cutting on the properties of clippings from electrical sheets. Acta Metallurgica Slovaca, Vol. 21, No. 4, pp. 302-310.

[5] Naumoski, H., Riedmüller, B., Minkow, A., Herr, U. (2015). Investigation of the influence of different cutting procedures on the global and local magnetic properties of non-oriented electrical steel. Journal of Magnetism and Magnetic Materials, Vol. 392, pp.126-133.

[6] Weiss, H. A., Trober, P., Golle, R., Steentjes, S., Leuning, N., Elfgen, S., Hameyer, K., Volk, W. (2018). Impact of Punching Parameter Variations on Magnetic Properties of Non-Grain Oriented Electrical Steel. IEEE Transactions on Industry Applications, Vol. 54, No. 6, pp. 5869-5878.

[7] LoBue, M., Sasso, C., Basso, V., Fiorillo, F., Bertotti, G. (2000). Power losses and magnetization process in Fe-Si non-oriented steels under tensile and compressive stress. Journal of Magnetism and Magnetic Materials, Vol. 215-216, pp. 124-126.

[8] Spišák, E., Kaščák, L., Majerníková, J., Džupon, M. (2017). Analysis of 
cutting surface during cutting of electric sheets. Strength of Materials, Vol. 49, No. 4, pp. 605-611.

[9] Majerníková, J., Spišák, E. (2017). Increasing Durability of Cutting Tools. Advances in Science and Technology Research Journal, Vol. 11, No. 4, pp. 141-146.

\section{Biographical notes}

Ján Slota, prof. Ing. PhD., (1974). Currently works as full professor at Department of Computer Support of Technology. He graduated on Faculty of Mechanical Engineering, Technical University of Košice, where he received also scientific degree PhD in 2002. Full professor position in the university reached in 2017. His research field is oriented on modeling and numerical simulation of sheet metal forming processes. He is a member of The International Deep - Drawing Research Group (IDDRG). He has been worked on several grant projects, research tasks and many projects solved for industry. He is author of 2 monographs, 7 university textbook and more than 160 publications in journals and conference proceedings at Slovakia and abroad. He has 110 citations indexed within Web of Science Core Collection.

Luboš Kaščák, doc. Ing. PhD., (born in 1974) is an associate professor at the Institute of Technology and Materials Engineering, Faculty of Mechanical Engineering, Technical University of Košice. He graduated from the Faculty of Mechanical engineering in 1999. He works in the area of evaluation of properties of joined steel sheets, focusing on resistance spot welding, adhesive bonding and mechanical joining. He is the author of 2 monographs and more than 150 publications in journals and conference proceedings in Slovakia and abroad. His published works were cited more than 100 times. He has been involved in several grant projects and research tasks.

Stanislaw Kut, Dr hab. inz., (born in 1975 in Ropczyce, Poland). He received his PhD. degree at Rzeszow University of Technology in 2004. The degree of a habilitated doctor in the field of technical sciences (discipline of mechanics) was obtained in 2013. Since 2004 he is an assistant professor at the Department of Materials Forming and Processing, Faculty of Mechanical Engineering and Aeronautics, Rzeszow University of Technology. His research and scientific activity is mainly focused on issues in the field of metal forming processes, in particular: modeling with the use of nonlinear FEM, designing of non-standard processes, devices and instrumentation. He is autor of 2 monographies, 9 patents, 10 patent applications and more than 120 publications in scientific journals and conference proceedings.

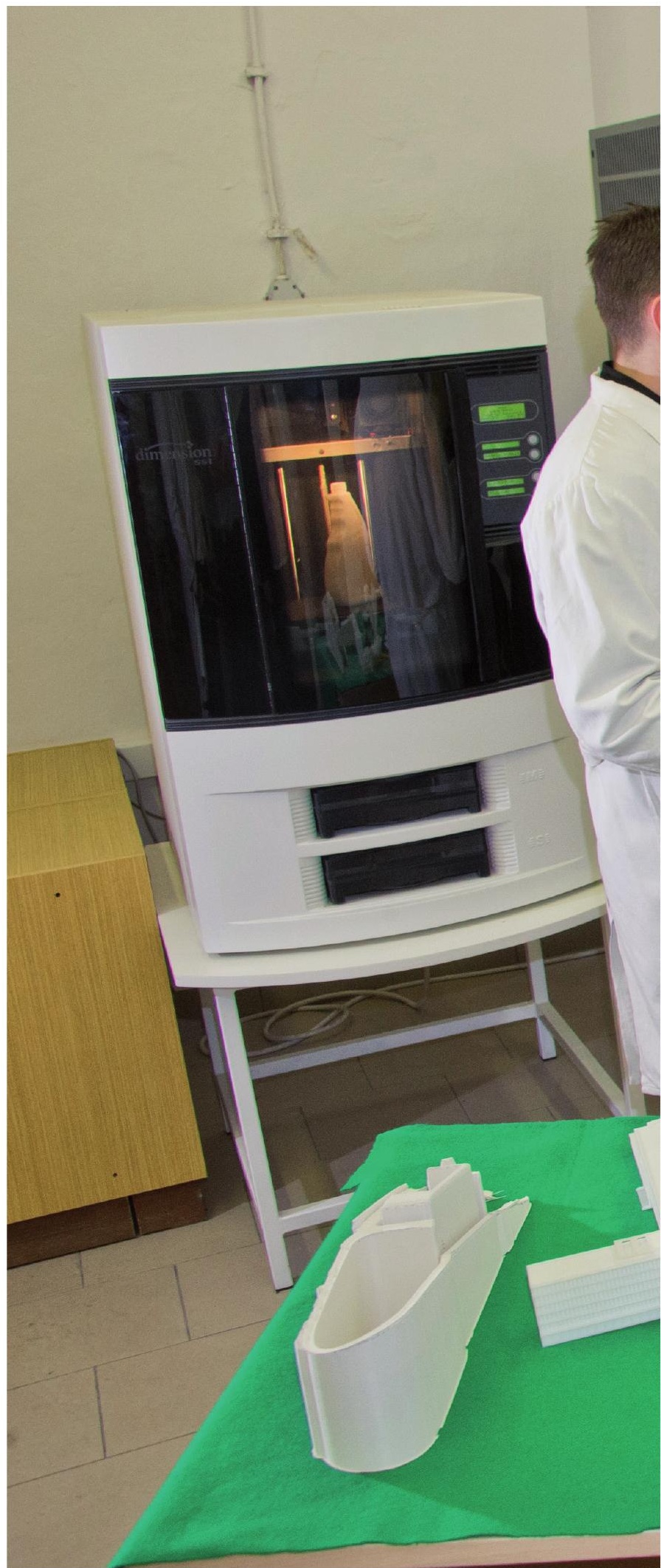

